\title{
LED Lighting Implementation as a Strategy for Energy Saving in Energetically Sustainable Campus
}

\author{
Pablo Pérez-Gosende ${ }^{1,2, *}$
}

${ }^{I}$ Grupo de Investigación Interdisciplinar en Matemática Aplicada (GIIMA), Universidad Politécnica Salesiana, 090109, Ecuador

${ }^{2}$ Centro de Investigación en Gestión e Ingeniería de Producción (CIGIP), Universitat Politècnica de València, Alcoy, 03801, Spain

A R T I C L E IN F O

Article history:

Received: 04 August, 2019

Accepted: 13 September, 2019

Online: 22 October, 2019

Keywords:

AHP

Dialux

Energy-saving strategy

LED lighting

\begin{abstract}
A B S T R A C T
Since lighting constitutes an important part of the total electricity consumption of a country, the design and implementation of more efficient interior lighting systems are one of the feasible strategies to reduce energy consumption. With this purpose, in recent years several studies have considered the use of LED lighting systems. However, its implementation at a large scale is still unaffordable for some organizations like academic institutions. In this context, this research presents a strategy to replace the current fluorescent-based lighting system to LED technology in a building of a higher education institution in Ecuador, and thus contribute to reducing energy consumption in campus facilities. The appropriate LED lamp alternative was selected from those available in the Ecuadorian market through AHP multicriteria decision-making method. The improvement proposal included an annual schedule for the progressive replacement of fluorescent lamps, based on the economic savings that would be generated every year after its implementation. The proposal was technically validated by simulation in DIAlux 4.12 and its economic feasibility was demonstrated by estimating the net present value and the equivalent uniform annual cost. With this strategy, a total of 2595 fluorescent tubes installed in the 215 building light points, can be replaced with LED technology in three years, with an initial investment of 4949.10 USD and generate an energy saving of $47.36 \%$.
\end{abstract}

\section{Introduction}

Given the high level of pollution generated in the environment by the production of electricity based on fossil fuels, it is evident that there is a need to draw up strategies to reduce energy consumption. For this purpose, one of the feasible strategies consists in the design and implementation of more efficient interior lighting systems [1], since lighting constitutes an important part of a country's total electricity consumption [2]. It has been reported that in industrialized countries, lighting represents $20 \%$ of the total energy consumption [3].

The optimization of indoor lighting systems is a matter of great interest to the scientific community [4]. Approximately $21 \%$ of all the electricity produced in the world is consumed in lighting [5]. Some more specific studies show that the electric energy consumed by lighting systems represents $50 \%$ of the total energy consumption in office buildings, between $20 \%$ and $30 \%$ in hospitals, $15 \%$ in manufacturing factories and from 10 to $15 \%$ in schools $[4,6]$.

*P. Pérez-Gosende, Chambers 227, Guayaquil, Ecuador, pperezg@ups.edu.ec
In the USA approximately $31 \%$ of all electrical consumption in academic buildings is due to lighting systems [7]. In Europe, this value is approximately 50\% [8]. The reduction of energy consumption through the design and implementation of more efficient lighting systems is an important solution to the problem [5], but not the only one. Other possible ways to reduce the energy consumption related to lighting in buildings include the creation of awareness in the users, the adjustment or organization of the furniture and other elements within the space in a way that allows to take advantage of the natural light that enters through the windows, or the installation of motion sensors and control systems that modulate the intensity of the light according to the needs or turn it off when the space is not being occupied.

In recent years, several studies have considered the implementation of LED lighting (Light-Emitting Diodes) to reduce the electricity consumption of the facilities and thus contribute to the energy efficiency in buildings $[1,4,5,9,10]$. LED lighting has gained special relevance in recent years over traditional lighting technologies due to its high efficiency, long 


\section{P. Pérez-Gosende. / Advances in Science, Technology and Engineering Systems Journal Vol. 4, No. 5, 360-368 (2019)}

lifespan and low maintenance cost. However, its impact on energy savings in industrialized countries has been questioned [3].

LEDs can produce high luminous fluxes with low heat emission and maintain their light output efficiency for years. Incandescent (IL) and fluorescent (FL) bulbs contain filaments that must be replaced periodically and consume a lot of electrical energy while generating heat [11]. The duration of the fluorescent bulbs is of the order of 20,000 hours, while the incandescent bulbs last approximately 1000 hours. LEDs, on the other hand, do not have filaments, and therefore, they do not burn like incandescent or fluorescent bulbs. Normally, commercial LED lamps have a lifespan of 30,000 to 50,000 hours.

The design of an interior lighting system should consider, in addition to energy efficiency, the visual performance and comfort of users [5]. Particularly in educational institutions, the implemented lighting systems should provide a pleasant and stimulating environment that allows students, teachers and administrative staff in general, to perform their activities without excessive visual effort, avoiding fatigue, headaches and the prevalence of vision disorders provoked by inadequate lighting [12]. For this reason, the lighting system in educational institutions should be monitored with a certain frequency to guarantee the correct development of the teaching-learning processes.

In Ecuador, the 2393 Executive Decree that regulates the levels of lighting is not very demanding, or at least not very precise in terms of the levels of lighting suitable for each activity [13]. On the other hand, public or private institutions are not required to carry out light audits to detect deficiencies in lighting systems. Therefore, it is extremely important to give concrete answers to the reduction of energy consumption in Higher Education Institutions (HEIs) by searching for more efficient lighting alternatives without neglecting compliance with current regulations regarding health and safety.

In this context, this study proposes an energy-saving strategy based on the progressive implementation of LED lighting in an academic building of an HEI located in the city of Guayaquil.

This research is part of a wider scope project named "Sustainable Energy Campus Model" developed by the Interdisciplinary Research Group in Applied Mathematics (GIIMA) of the Universidad Politécnica Salesiana in conjunction with the Interdisciplinary Modeling Group (InterTech) of the Universitat Politècnica de València. The results of the project will allow, in the medium term, to optimize the energy consumption for lighting, air conditioning and the use of computers in the institution. The future savings generated by the improvements proposals within this project could further strengthen the university infrastructure, especially in the setting and equipment of new laboratories and the increase and updating of the literary heritage available in the university library.

\section{Methods}

The research is quantitative with a descriptive approach. The HEI under study is located in the city of Guayaquil, Ecuador, and is composed of six buildings. These, in turn, are composed mostly of classrooms, laboratories, teacher workrooms, administrative offices, auditoriums, hallways, bathrooms, and storage areas.

Illuminance measurements were taken in the facilities of one of these buildings between October 2017 and February 2018 by four AMPROBE lux meters model LM100, with an accuracy of \pm $5 \%+5$ digits. The dimensions of the facilities, as well as the distance from the work surface to the light points, were obtained through a Capital laser distance meter, model CP-3007, with an accuracy of $\pm 0.5 \%$ and resolution of $0.01 \mathrm{~m}$.

The replacement strategy of the current lighting system based on FL to LED technology, included an annual schedule for the progressive replacement of fluorescent lamps, based on the economic savings that would be generated every year after its implementation. For this, the LED lamp alternative suitable for the building's facilities was selected from those available in the Ecuadorian market using the AHP multicriteria method [14].

For the improvement proposal technical validation, it was used DIALux 4.12 software. Facilities were modeled and the lighting levels that would be obtained once the lamps were installed were simulated. In this regard, it was possible to verify in each case the fulfillment of the minimum illuminance requirements established in the national and international regulations used as a reference in this work [12,13].

For the economic validation of the improvement proposal, using (1), the net present value (NPV) of the costs was calculated and compared for the two project alternatives: (A) The progressive replacement to LED lighting or (B) to keep the current FL-based lighting system.

$$
N P V=\sum_{j=1}^{n} P V_{j}
$$

By progressively replacing the current FL-based lighting system with LED technology, energy consumption will decrease and this will generate economic savings. This saving has been taken into account in this investigation for the determination of the annual present value $\left(\mathrm{PV}_{\mathrm{j}}\right)$, considering as such the updated value of the difference between the total costs $\left(\mathrm{TC}_{\mathrm{j}}\right)$ and the future annual benefits $\left(\mathrm{ES}_{\mathrm{j}}\right)$ as presented in (2).

$$
P V_{j}=\left(T C_{j}-E S_{j}\right) \cdot\left[1 /(1+i)^{j}\right]
$$

Likewise, the economic analysis included the equivalent annual uniform cost estimation (EAUC) for each alternative throughout its expected time horizon. EAUC consists of converting all expenditures into a uniform series of payments [15] and is frequently used in the evaluation of investment projects where revenues are not relevant, but costs. It is formulated as in (3) and its value depends on the capital cost or discount rate (i) and the NPV of the amounts of cash outflows from year $j=0$ to year $\mathrm{j}=\mathrm{n}$. When comparing several alternatives of mutually exclusive projects, the one with minor EAUC should be selected $[15,16]$.

$$
E A U C=N P V\left[i(1+i)^{n} /(1+i)^{n}-1\right]
$$

The relevant benefits and costs items for NPV calculation (expressed in \$/year) are obtained from the following equations. There, AC represents the annual cost of lamps acquisition, EC the annual electricity consumption cost, DC the cost of the final disposal of the fluorescent lamps that are replaced and ES corresponds to the annual economic benefit that represents the energy savings by the use of LED lamps instead of FL. In addition, $\mathrm{L}$ represents the quantity of lamps expressed in units $(\mathrm{u}), \operatorname{Pr}$ the wholesale price of the lamp (\$/u), P the power of the lamp (W), H 
the estimated daily use time of the lamp, D the number of days per year in which the institution operates and $\mathrm{T}$ is the electric rate $(\$ / \mathrm{kWh})$. Also, $\mathrm{W}_{\mathrm{FL}}$ refers to the average weight of a $60 \mathrm{~cm}$ long fluorescent lamp $(\mathrm{Kg} / \mathrm{u})$ and $\operatorname{PrD}$ means the price of the specialized recycling service for the final disposal of $\mathrm{FL}(\$ / \mathrm{Kg})$.

$$
\begin{gathered}
T C_{j}=A C_{j}+E C_{j}+D C_{j} \\
A C_{j}=L \cdot P r \\
E C_{j}=0.001 \cdot L \cdot P \cdot H \cdot D \cdot T \\
D C_{j}=W_{F L} \cdot L_{F L} \cdot P r_{D} \\
E S_{j}=0.001 \cdot L_{L E D} \cdot H \cdot D \cdot T \cdot\left(P_{F L}-P_{L E D}\right)
\end{gathered}
$$

\section{Results}

In this section it is reported the results of the light audit, the selection of the most suitable LED lamp alternative for educational facilities according to certain relevant factors, the proposed replacement schedule and the technical and economic validation of the improvement proposal.

\subsection{Indoor lighting audit}

The building under study is one of the six that comprise the campus. There were identified 50 classrooms, 4 hallways, 18 restrooms, 8 computer laboratories, 4 teacher workrooms, 5 administrative offices, a medical department, a supply warehouse, a restaurant/coffee shop and a copy center, all of them illuminated by $60 \mathrm{~cm}$ long linear fluorescent lamps with powers of 17, 18 and 32W. 215 light points and 2595 fluorescent tubes were counted throughout the building. The chapel, the theater, and the auditoriums do operate with compact fluorescent lamps (CFL) downlight style.

In the building, several careers carry out their daily academic activities in three sessions: morning (07h00-13h00), evening (14h00-18h00) and night (18h00-22h15). The existence of a night session facilitates the students to work and attend University at the same time and is one of the differentiating elements of this HEI in the city. After the last shift of classes, it takes an hour for the cleaning team to organize all the classrooms for the next day.

According to the above, in this study, it has been considered that the lighting system remains on 16 hours a day, 288 days a year. The illuminance measurements were made at night, between 7:00 p.m. and 10:00 p.m. In each location, illuminance measurements were taken at the height of the work surface $(0.77 \mathrm{~m}$ in classrooms and $0.8 \mathrm{~m}$ in laboratories) at five different points, and the average value was taken as a reference.

The legislation that regulates indoor and outdoor lighting levels in Ecuador is the 2393 Executive Decree: Regulation of safety and health of workers and improvement of the work environment [13], however, this norm does not establish specific illuminance values for academic activities given its generality. From its content, it is assumed that the reading and writing activities that take place in a classroom, as well as those that take place in a computer laboratory, can be done with a minimum lighting level of $300 \mathrm{~lx}$ since in these cases the average distinction of details is essential. In these facilities would not be justified an illuminance of $500 \mathrm{~lx}$, which is the value established in the standard for works in which a fine distinction of details under conditions of contrast is indispensable.

Given the lack of specificity in the Ecuadorian regulations, this research also took as a reference to the European standard on indoor lighting EN 12464.1, which includes minimum illuminance values for educational establishments [12]. Table 1 shows a comparison of the levels of illumination allowed for the facilities at the academic building under study in this investigation according to both regulations. In case of disparity, the highest minimum permissible illuminance value was taken as reference.

According to the above, it was identified that $98 \%$ of the building facilities do not comply with the lighting requirements established in the national regulation and the European standard for indoor lighting. Note also that only the chapel and the restaurant/coffee shop meet the reference standard used in this investigation.

The noncompliance with the lighting levels required for the facilities was corroborated through its simulation in DIAlux 4.12. Taking as an example a standard classroom model of $6.80 \mathrm{~m} \mathrm{x}$ $6.70 \mathrm{~m} \times 3.25 \mathrm{~m}$, considering a maintenance factor of 0.8 , a height of the work plane of $0.77 \mathrm{~m}$, six light points and three FL lamps of $17 \mathrm{~W}$ in every light point, the resulting illuminance isoline diagram (Figure 1) shows illuminance values below the $300 \mathrm{~lx}$ requirement established in regulations for this type of facility.

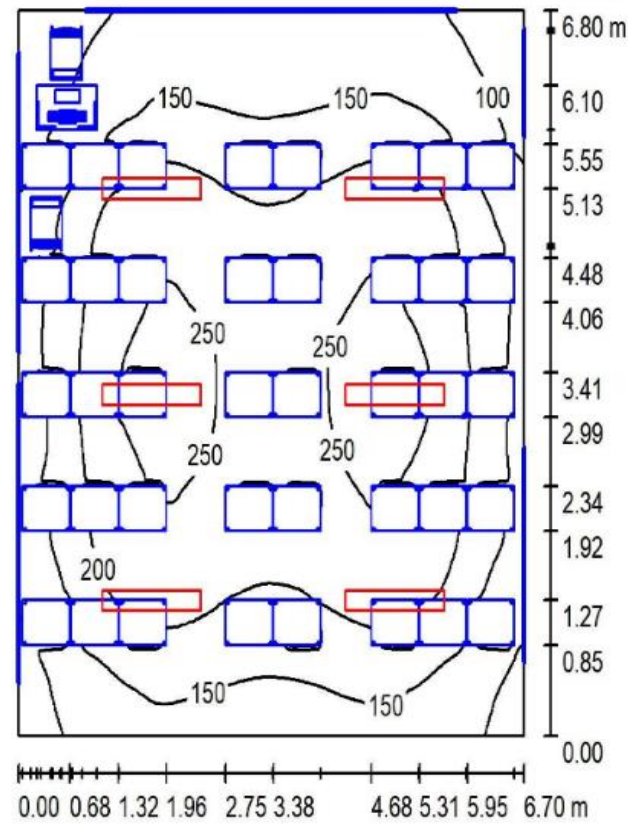

Figure 1: Illuminance isoline diagram for a standard model classroom

\subsection{LED lamps selection}

To verify more economical lighting alternatives and contribute to the campus energy saving, it was decided to implement LED lighting, as this technology is more efficient, generates less consumption given its low power, in addition to its longer lifespan.

Unified Glare Index, UGR), efficiency ( $\mathrm{lm} / \mathrm{W})$ and light type. Then, as all the identified alternatives provided light in a neutral white tone and had a UGR $<19$, the criteria type light and glare were discarded from the final decision process. 
Table 1: Compliance with illuminance reference standards for academic buildings

\begin{tabular}{|c|c|c|c|c|c|c|c|c|c|}
\hline \multirow[t]{2}{*}{ Facilities } & \multicolumn{2}{|c|}{ Standard } & \multirow{2}{*}{$\begin{array}{l}\text { Reference } \\
\text { standard }\end{array}$} & \multirow{2}{*}{$\begin{array}{r}\text { Total of } \\
\text { facilities }\end{array}$} & \multirow{2}{*}{$\begin{array}{l}\text { Facilities that } \\
\text { do not meet } \\
\text { the standard }\end{array}$} & \multicolumn{2}{|c|}{$\begin{array}{l}\text { Measured } \\
\text { illuminance }\end{array}$} & \multicolumn{2}{|c|}{$\begin{array}{l}\text { Illuminance } \\
\text { needed to meet } \\
\text { the standard }\end{array}$} \\
\hline & $\begin{array}{c}\text { Decree } \\
\text { No. } 2393\end{array}$ & EN 12464.1 & & & & $\mu$ & $\sigma$ & $\mu$ & $\sigma$ \\
\hline Classrooms & $3001 x$ & $3001 x$ & $3001 x$ & 50 & 50 & 130 & 46.30 & 170 & 46.30 \\
\hline Hallways & $201 x$ & $1001 x$ & $1001 x$ & 4 & 4 & 54 & 12.53 & 47 & 12.53 \\
\hline Restrooms & $50 \mathrm{~lx}$ & $2001 x$ & $200 \mathrm{~lx}$ & 18 & 18 & 35 & 8.03 & 165 & 8.03 \\
\hline $\begin{array}{l}\text { Computer } \\
\text { laboratories }\end{array}$ & $3001 x$ & $3001 x$ & $3001 x$ & 8 & 8 & 139 & 36.60 & 161 & 36.60 \\
\hline $\begin{array}{l}\text { Teacher } \\
\text { workrooms }\end{array}$ & $\begin{array}{c}\text { Not } \\
\text { specified }\end{array}$ & $3001 x$ & $3001 x$ & 4 & 4 & 112 & 38.24 & 189 & 38.24 \\
\hline $\begin{array}{l}\text { Administrative } \\
\text { offices }\end{array}$ & $3001 x$ & $3001 x$ & 300 lx & 5 & 5 & 113 & 33.68 & 187 & 33.68 \\
\hline $\begin{array}{l}\text { Medical } \\
\text { department }\end{array}$ & $\begin{array}{c}\text { Not } \\
\text { specified }\end{array}$ & $5001 x$ & $5001 x$ & 1 & 1 & 225 & 0 & 275 & 0 \\
\hline Warehouse & $200 \mathrm{~lx}$ & $100 \mathrm{~lx}$ & $2001 x$ & 1 & 1 & 140 & 0 & 60 & 0 \\
\hline $\begin{array}{l}\text { Restaurant and } \\
\text { coffee shop }\end{array}$ & $\begin{array}{c}\text { Not } \\
\text { specified }\end{array}$ & $\begin{array}{c}{ }^{\mathrm{a}} \text { Not } \\
\text { specified }\end{array}$ & $100 \mathrm{~lx}$ & 1 & 0 & 260 & 0 & 0 & 0 \\
\hline Chapel & $\begin{array}{c}\text { Not } \\
\text { specified }\end{array}$ & $\begin{array}{c}\text { Not } \\
\text { specified }\end{array}$ & $100 \mathrm{~lx}$ & 1 & 0 & 178 & 0 & 0 & 0 \\
\hline Copy center & $3001 x$ & $300 \mathrm{~lx}$ & $300 \mathrm{~lx}$ & 1 & 1 & 145 & 0 & 355 & 0 \\
\hline Theater & $\begin{array}{c}\text { Not } \\
\text { specified }\end{array}$ & $\begin{array}{c}\text { Not } \\
\text { specified }\end{array}$ & $100 \mathrm{~lx}$ & 1 & 1 & 84 & 0 & 16 & 0 \\
\hline Auditoriums & $\begin{array}{c}\text { Not } \\
\text { specified }\end{array}$ & $5001 x$ & $5001 x$ & 2 & 2 & 169 & 43 & 331 & 43 \\
\hline
\end{tabular}

${ }^{a}$ For this case, the European standard states as appropriate any value of illuminance that allows creating an appropriate atmosphere. Source: Own elaboration based on the requirements in the national and European standards referred to in $[12,13]$.

The decision criteria that were taken into account for LED lamp selection were: power (W), lifespan (h), wholesale price (USD), color rendering index (CRI), glare (measured by the

The hierarchical decision model followed in this research for the selection of the LED lamp by the Saaty Analytical Hierarchic Process (AHP) is shown in Figure 2. In the scheme, the zero level represents the decision objective, the level one the decision criteria considered, and level two presents a selection of the few alternatives of linear $60 \mathrm{~cm}$ long LED lamps available in the Ecuadorian market that could be installed in the bases of existing fluorescent luminaires. This last consideration was necessary to reduce the cost of the replacement process, since LED luminaires, despite their benefits, currently continue to be more expensive than FL.

The comparison of the importance or preference between each pair of criteria using the Saaty scale [14], led to a reciprocal matrix (R) so that rij represents the relative priority between criterion $\mathrm{Ci}$ and criterion $\mathrm{Cj}$ with respect to the objective or goal of the problem.

$$
R=\left[\begin{array}{ccccc}
1 & 5 & 3 & 5 & 1 \\
1 / 5 & 1 & 1 / 3 & 5 & 1 / 5 \\
1 / 3 & 3 & 1 & 5 & 1 \\
1 / 5 & 1 / 5 & 1 / 5 & 1 & 1 / 5 \\
1 & 5 & 1 & 5 & 1
\end{array}\right]
$$

The results of the normalization of the paired comparisons are presented in the $\mathrm{R}_{\text {NORM }}$ matrix and the resulting priority vector in the $\mathrm{W}$ matrix.

$$
R_{\text {NORM }}=\left[\begin{array}{lllll}
0.3659 & 0.3521 & 0.5422 & 0.2381 & 0.2941 \\
0.0732 & 0.0704 & 0.0602 & 0.2381 & 0.0588 \\
0.1220 & 0.2113 & 0.1807 & 0.2381 & 0.2941 \\
0.0732 & 0.0141 & 0.0361 & 0.0476 & 0.0588 \\
0.3659 & 0.3521 & 0.1807 & 0.2381 & 0.2941
\end{array}\right]
$$

$$
W=\left[\begin{array}{l}
0.3585 \\
0.1002 \\
0.2092 \\
0.0460 \\
0.2862
\end{array}\right]
$$

The process of paired comparisons of the criteria yielded a consistency index of $9.08 \%$, so it is considered that the matrix R has an admissible consistency and the vector of priorities obtained (W) is accepted as valid.

As could be interpreted in Figure 2, all the decision criteria are quantitative variables, so it would not be relevant to make comparisons between alternatives concerning each variable using the subjective scale of Saaty. Consequently, with the values identified for each decision variable in each alternative, the $\mathrm{M}$ 
matrix was generated. Here, every mij represents the value that the lamp alternative $\mathrm{i}$ takes in variable $\mathrm{j}$.

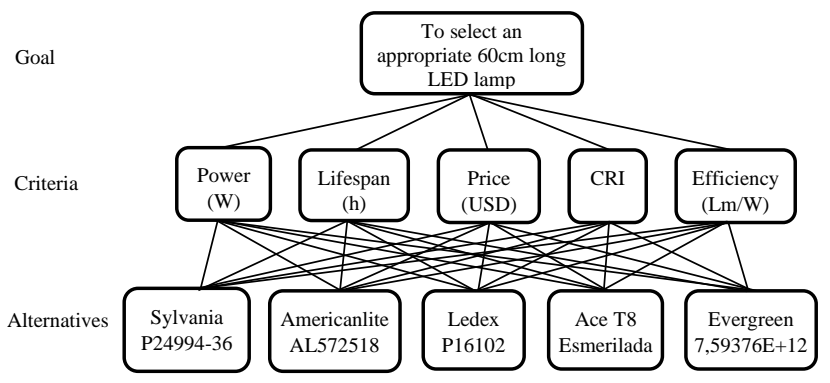

Figure 2: Hierarchical decision model for LED lamp selection

$$
M=\left[\begin{array}{ccccc}
9 & 25000 & 3.70 & 70 & 89 \\
9 & 40000 & 3.90 & 80 & 130 \\
9.5 & 30000 & 3.50 & 75 & 77 \\
9 & 25000 & 3.60 & 75 & 100 \\
10 & 30000 & 3.60 & 75 & 90
\end{array}\right]
$$

Note that the above mentioned power and wholesale price criteria are to be minimized, while lifespan, color performance, and efficiency are to be maximized. Thus, it was necessary to homogenize the M matrix to the MNORM matrix. The latter is composed of all the local priority vectors of the alternatives for each criterion.

$$
M_{\text {NORM }}=\left[\begin{array}{ccccc}
0.1 & 0.625 & 0.0513 & 0.8750 & 0.6846 \\
0.1 & 1 & 0 & 1 & 1 \\
0.05 & 0.75 & 0.1026 & 0.9375 & 0.5923 \\
0.1 & 0.625 & 0.0769 & 0.9375 & 0.7692 \\
0 & 0.75 & 0.0769 & 0.9375 & 0.6923
\end{array}\right]
$$

Then, the global priority vector of the alternatives was obtained from the multiplication of the alternative priority vectors concerning the decision criteria (MNORM matrix) with the priority vector of the criteria with respect to the objective (W matrix).

$$
M_{N O R M} \cdot W=\left[\begin{array}{l}
0.3453 \\
0.4681 \\
0.3271 \\
0.3778 \\
0.3324
\end{array}\right]
$$

From here it is concluded that the most suitable LED lamp alternative according to the previously defined decision criteria is the Americanlite AL572518. This LED tube, measuring $60 \mathrm{~cm}$ in length, emits neutral white light, has a power of $9 \mathrm{~W}, 40000 \mathrm{~h}$ of lifespan, wholesale price of $\$ 3.90$, IRC equal to $80, \mathrm{UGR}<19$ and average efficiency of $130 \mathrm{~lm} / \mathrm{W}$.

\subsection{Technical validation of the selected lamp}

Taking into account the selected lamp model, the facilities were modeled and the lighting system was simulated using the DIAlux 4.12 software.

Taking the simulation of a standard classroom as an example and considering three LED tubes in each of the six pre-existing light points, the resulting illuminance isoline diagram shows values equal to or greater than those established in the regulations for this type of facility (300 lx) in most of the useful area of the classroom (Figure 3). More specifically, the Dialux report showed an average illuminance value on the work plane of 326 lx, 204 lx on the floor, $70 \mathrm{~lx}$ on the ceiling and $52 \mathrm{~lx}$ on the walls.

On the other hand, the resulting color performance diagram is shown in Figure 4. The red color on the work surfaces ensures that if the selected LED lamp is implemented, without having to increase the number of light points, it is possible to guarantee the minimum illuminance requirements established in the regulations. This validates from the technical point of view the suitability of the selected lamp for the building's facilities, which are mostly classrooms with similar characteristics.

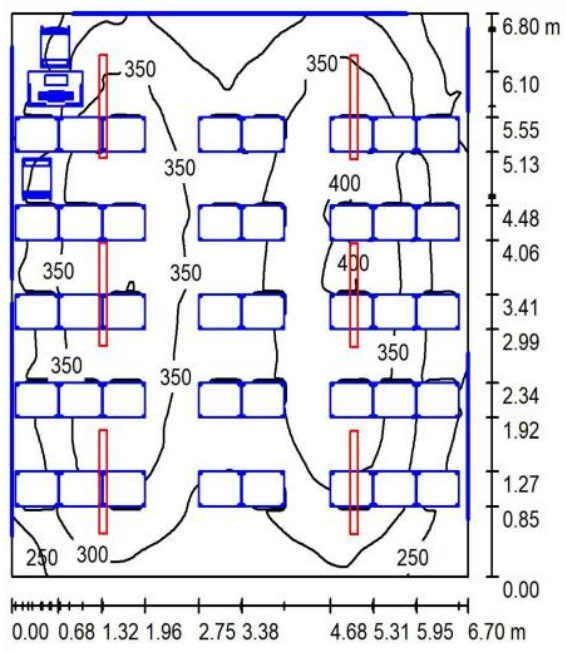

Figure 3: Illuminance isoline diagram for a standard model classroom

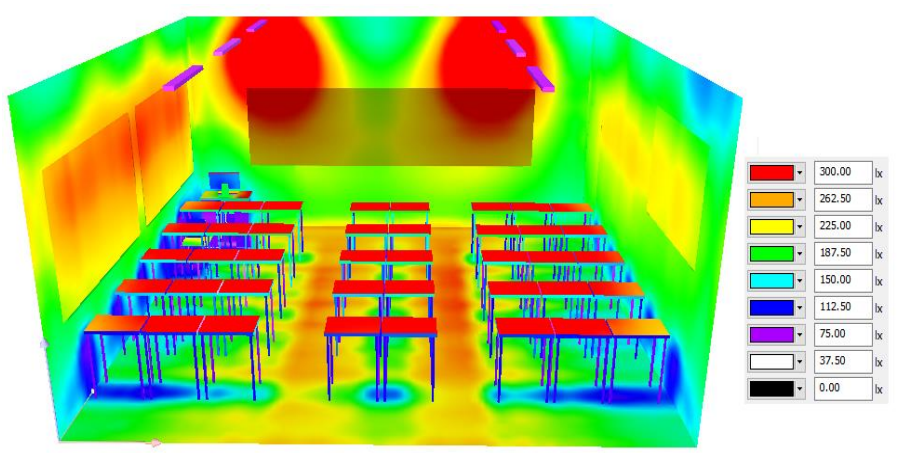

Figure 4: False color rendering

\subsection{Replacement strategy}

Given the high cost that comprises to shift all the fluorescent lamps at once, it is recommended the replacement to be gradual, prioritizing those facilities with greater gaps to meet the lighting standards. For the building under interest in this research, it is proposed to follow the lamp replacement schedule represented in Table 2 with their respective prioritization criteria. As may be seen, the classrooms and computer laboratories were prioritized, since within these facilities are commonly developed the academic activities that are the central axis of the University formative mission. 
Table 2: Schedule for replacement of FL by LED lamps

\begin{tabular}{|c|c|c|c|c|c|}
\hline Priority level & Facility & Quantity & ${ }^{\mathrm{a}}$ Priority criteria & Required lamps & Schedule \\
\hline 1 & Classrooms & 15 & $(\mathrm{RS}-\mathrm{IM}) \geq 200 \mathrm{~lx}$ & 405 & \multirow{2}{*}{ First year } \\
\hline 2 & Computer Laboratories & 7 & $(\mathrm{RS}-\mathrm{IM}) \geq 100 \mathrm{~lx}$ & 189 & \\
\hline 3 & Classrooms & 25 & $150 \leq(\mathrm{RS}-\mathrm{IM})<200 \mathrm{~lx}$ & 297 & \multirow{12}{*}{ Second year } \\
\hline 4 & Computer laboratories & 1 & $(\mathrm{RS}-\mathrm{IM})<100 \mathrm{~lx}$ & 27 & \\
\hline 5 & Classrooms & 10 & $(\mathrm{RS}-\mathrm{IM})<150 \mathrm{~lx}$ & 270 & \\
\hline 6 & Medical department & 1 & - & 12 & \\
\hline 7 & Teacher workrooms & 4 & - & 144 & \\
\hline 8 & Administrative offices & 5 & - & 135 & \\
\hline 9 & Auditoriums & 2 & - & 78 & \\
\hline 10 & Hallways & 4 & - & 324 & \\
\hline 11 & Warehouse & 1 & - & 3 & \\
\hline 12 & Copy center & 1 & - & 18 & \\
\hline 13 & Theater & 1 & - & 49 & \\
\hline 14 & Restaurant and coffee shop & 1 & - & 12 & \\
\hline 15 & Chapel & 1 & - & 38 & \multirow{2}{*}{ Third year } \\
\hline 16 & Restrooms & 18 & - & 216 & \\
\hline
\end{tabular}

${ }^{a}$ RS represents the value of the reference illuminance standard according to regulations. IM refers to the actual average illuminance measured in the facilities. In areas where no prioritization criteria were applied, all lamps will be replaced at the same time.

It is worth noting that as part of the replacement strategy and after the first year of the initial investment, it has been considered that the new lamps to be installed are to be obtained with the amount equivalent to the economic value saved by the institution the previous year due to the use of LED technology instead of fluorescent technology.

\subsection{Economic validation of the improvement proposal}

For the economic validation of the improvement proposal, two alternative strategies were considered: (A) To implement the progressive replacement to LED lighting proposed in this study or (B) To continue with the current FL-based lighting system. The energy consumption and annual economic expenditure estimated in each case are referred to in Table 3.

From the above, it is assumed that the current FL-based lighting system electricity costs represent on average $10.93 \%$ of the total electrical energy consumed in the building $(95 \% \mathrm{CI}$ : 9.89-11.98), taking into account that during the last 18 months of operation, the total average cost of the building was $\$ 13,657.94$ (95\% CI: 12434.50-14881.38).

The investment cycle for strategy (A) and (B), has an estimated time horizon of eight and two years, respectively, considering the average lifespan of the corresponding lamp, the 16 hours of daily use and the 288 days of annual operation of the institution. Then, since both alternatives are mutually exclusive and have different lifetimes, the comparison of their net present values must be made on the least common multiple of years, in this case, 8 years. According to this, Table 4 shows all possible expenditures and benefits for each alternative. In it, for the calculation of the present values of the annual differences between costs and benefits, the active interest rate of $7.26 \%$ established by the Central Bank of Ecuador for March 2018 [17] was considered as the minimum attractive rate of return (MARR).

It is important to clarify that in the estimation of the total costs there have not been considered salary expenses of the personnel that will perform the replacement of the fluorescent lamps for those with LED technology, given that the University has www.astesj.com maintenance personnel hired and their salaries are debited from the annual operations budget.

With the data in Table 4, a NPV of $\$ 56115.02$ was calculated for alternative 1 , while for alternative 2 the resulting NPV was $\$ 133188.18$. Then, with the updated values of the differences between costs and benefits, the EUAC was estimated for each alternative considering their respective life cycles. In this regard, the strategy of the progressive switch to LED lighting yielded a EUAC equal to $\$ 8868.28$, while the alternative of doing nothing and maintain the current FL lighting system was $\$ 20669$.26. This result shows that the alternative based on LED technology has lower NPV and lower EUAC, which means it is the most feasible alternative from the economic point of view.

Finally, the graph in Figure 5 shows the trend of total costs for both alternatives over time, in addition to the behavior of economic savings and the acquisition cost of LED lamps.

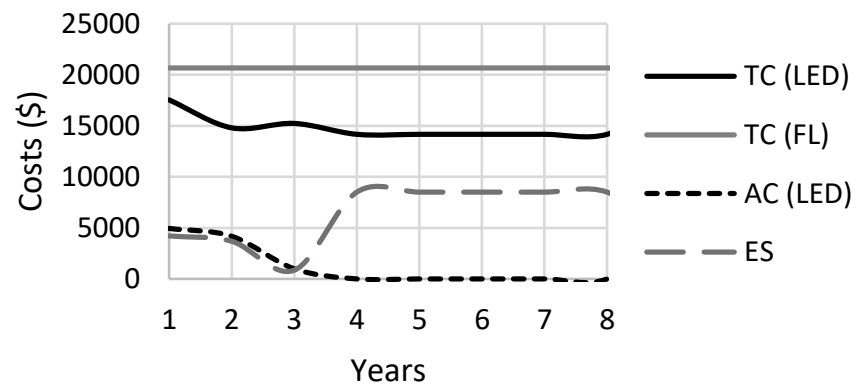

Figure 5: Some relevant cost functions

As can be seen in Figure 5, the strategy of progressive replacement to LED lighting (Strategy a) is less costly during the replacement period (three years) and during the rest of the investment's life cycle. In the same way, it is observed that once the total conversion of the system has been made, the economic saving for the use of LED lighting (with respect to the current system based on FL) would cover the acquisition costs of the new luminaires that are needed at the end of the investment life, guaranteeing the sustainability in time of the proposed system. 
Table 3: Energy consumption and annual electricity expenditure for lighting systems based on FL and LED

\begin{tabular}{|c|c|c|c|c|c|c|c|c|}
\hline \multirow[b]{2}{*}{ Facilities } & \multirow[b]{2}{*}{ Quantity } & \multirow[b]{2}{*}{$\begin{array}{l}\text { Total of } \\
\text { lamps }\end{array}$} & \multicolumn{3}{|c|}{ FL Lighting system } & \multicolumn{3}{|c|}{ LED Lighting system } \\
\hline & & & $\begin{array}{c}\text { Power } \\
\text { consumed } \\
(\mathrm{kW})\end{array}$ & $\begin{array}{c}\text { Power } \\
\text { consumption } \\
\text { (kWh/year) }\end{array}$ & $\begin{array}{c}\text { Energy } \\
\text { cost } \\
\text { (\$/year) }\end{array}$ & $\begin{array}{c}\text { Power } \\
\text { consumed } \\
(\mathrm{kW})\end{array}$ & $\begin{array}{c}\text { Power } \\
\text { consumption } \\
\text { (kWh/year) }\end{array}$ & $\begin{array}{c}\text { Energy } \\
\text { cost } \\
\text { (\$/year) }\end{array}$ \\
\hline Classrooms & 50 & 1350 & 22.95 & 105753.60 & 9517.82 & 12.15 & 55987.20 & 5038.85 \\
\hline Hallways & 4 & 324 & 5.508 & 25380.86 & 2284.28 & 2.916 & 13436.93 & 1209.32 \\
\hline Restrooms & 18 & 216 & 3.672 & 16920.58 & 1522.85 & 1.944 & 8957.95 & 806.22 \\
\hline $\begin{array}{l}\text { Computer } \\
\text { laboratories }\end{array}$ & 8 & 216 & 3.672 & 16920.58 & 1522.85 & 1.944 & 8957.95 & 806.22 \\
\hline $\begin{array}{l}\text { Teacher } \\
\text { workrooms }\end{array}$ & 4 & 144 & 2.448 & 11280.38 & 1015.23 & 1.296 & 5971.97 & 537.48 \\
\hline $\begin{array}{l}\text { Administrative } \\
\text { offices }\end{array}$ & 5 & 135 & 2.295 & 10575.36 & 951.78 & 1.215 & 5598.72 & 503.88 \\
\hline $\begin{array}{l}\text { Medical } \\
\text { department }\end{array}$ & 1 & 12 & 0.216 & 995.33 & 89.58 & 0.108 & 497.66 & 44.79 \\
\hline Warehouse & 1 & 3 & 0.054 & 248.83 & 22.39 & 0.027 & 124.42 & 11.20 \\
\hline $\begin{array}{l}\text { Restaurant and } \\
\text { coffee shop }\end{array}$ & 1 & 12 & 0.384 & 1769.47 & 159.25 & 0.108 & 497.66 & 44.79 \\
\hline Chapel & 1 & 38 & 0.684 & 3151.87 & 283.67 & 0.342 & 1575.94 & 141.83 \\
\hline Copy center & 1 & 18 & 0.306 & 1410.05 & 126.90 & 0.162 & 746.50 & 67.18 \\
\hline aTheater & 1 & 49 & 0.882 & 31.75 & 2.86 & 0.441 & 15.88 & 1.43 \\
\hline${ }^{\mathrm{a}}$ Auditoriums & 2 & 78 & 1.404 & 808.70 & 72.78 & 0.702 & 404.35 & 36.39 \\
\hline Total & 97 & 2595 & 22.95 & 195247.37 & 17572.26 & 23.36 & 102773.12 & 9249.58 \\
\hline
\end{tabular}

${ }^{\mathrm{a}}$ In the case of the auditoriums, an average use of $2 \mathrm{~h}$ per day was considered, and for the theater $8 \mathrm{~h}$ per month, wich is equivalent to $0.3 \mathrm{~h}$ per day.

\section{Discussion}

This research shows that the progressive implementation of LED lighting in an academic building is a strategy that can contribute substantially to the energy and economic savings of a Higher Education Institution.

A lighting audit found that $98 \%$ of the building's facilities do not meet the illuminance requirements included in national and international regulations $[12,13]$. Likewise, it was detected that the energy consumption of the current FL-based lighting system represents $10.93 \%$ of the total electric energy consumed in the building, a value considered high, despite being located within the range of 10 to $15 \%$ identified by other similar studies in educational institutions $[4,6]$.

These reasons justify the need to implement a strategy to optimize energy saving through lighting system in the building, which at the same time, favors the performance and visual comfort of users through compliance with current regulations on occupational health and safety.

In response to this need, this research presents a strategy for the progressive replacement of the current FL-based lighting system to LED lighting, with a duration of three years, which guarantees compliance with the minimum levels of lighting required by national and international regulations for each facility and allows to obtain an energy saving of $47.36 \%$. This value would represent an economic saving of $\$ 8322.68$ per year for the institution and would allow the total coverage of the new luminaires that are needed at the end of the investment lifecycle.

Since the instantaneous conversion to LED lighting can be unfeasible from the economic point of view due to the high amount of the initial investment, the strategy suggested in this research prioritizes the replacement in those facilities with a greater need for illuminance to meet the requirements on national and European regulations. In this concern, the planned replacement of lamps can be covered with the amount equivalent to the economic value saved by the institution the previous year due to the use of LED technology instead of FL technology. Another element of importance to highlight in order to reduce installation costs was the consideration of the same number of preexisting light points.

According to the above, the amount of the initial investment of $\$ 4949.10$ will allow replacing $48.90 \%$ of the lighting system. Then, with the energy savings of the first year, 1072 LED lamps could be acquired to increase coverage to $90.21 \%$. Finally, with the energy savings of the second year, the remaining 254 lamps can be acquired to cover $100 \%$ of the building's needs according to the planned schedule.

The technical validity of the improvement proposal was obtained by modeling and simulating all the building's facilities in the free software DIALux, which is one of the most commonly used tools in lighting systems simulation [1,4,5,9,10,18-21]. In this regard, this research demonstrates that the results of the simulation in DIALux are very similar to those on-site 
P. Pérez-Gosende. / Advances in Science, Technology and Engineering Systems Journal Vol. 4, No. 5, 360-368 (2019)

Table 4. Costs and benefits of the alternatives: (a) Progressive change to LED lighting and (b) Current lighting system based on FL

\begin{tabular}{|c|c|c|c|c|c|c|c|c|c|}
\hline Alternatives & $\begin{array}{l}{ }^{\mathrm{a}} \text { Cost } \\
\text { ítems }\end{array}$ & Year 1 & Year 2 & Year 3 & Year 4 & Year 5 & Year 6 & Year 7 & Year 8 \\
\hline \multirow{7}{*}{$\begin{array}{l}\text { (A) } \\
\text { Progressive swift } \\
\text { to LED lighting }\end{array}$} & $\bar{a}$ & 4949.10 & 180.80 & 90.60 & U & U & 0 & 0 & 0 \\
\hline & $\mathrm{b}$ & 4736 & 99 & 14167.56 & 141 & 141 & 141 & 141 & 14167.56 \\
\hline & $\mathrm{c}$ & 7465 & 1806 & 0 & 0 & 0 & 0 & 0 & 0 \\
\hline & $\mathrm{d}$ & 390.85 & 330.18 & 78.23 & 0 & 0 & 0 & 0 & 0 \\
\hline & $\mathrm{e}$ & 17542.05 & 14800.49 & 15236.39 & 14 & 14 & 14 & 56 & 141 \\
\hline & $\mathrm{f}$ & 4210.24 & 3690.18 & 858.47 & 85 & & & & .14 \\
\hline & $\mathrm{g}$ & 12429.44 & 9657.19 & 116 & & & & & 2.78 \\
\hline \multirow{5}{*}{$\begin{array}{l}\text { (B) } \\
\text { Maintain the } \\
\text { current FL-based } \\
\text { lighting system }\end{array}$} & $\mathrm{a}$ & 2334.60 & 2334.60 & & & & & & .60 \\
\hline & $\mathrm{c}$ & 17935.19 & 17935.19 & 1793 & & 179 & & .19 & 17935.19 \\
\hline & $\mathrm{d}$ & 399.48 & 399.48 & 399.48 & & 399 & & 399.48 & 399.48 \\
\hline & $\mathrm{e}$ & 20669.2 & 20669.26 & & & & & 20669.26 & 20669.26 \\
\hline & $\mathrm{g}$ & 19270.24 & 17965.92 & 16749.88 & 15616.15 & 14559.15 & 13573.70 & 12654.95 & 11798.39 \\
\hline
\end{tabular}

${ }^{a}$ The cost items considered are: a) Acquisition, b) Annual energy consumption in LED lighting, c) Annual energy consumption in FL lighting d) Cost of the final

disposal of FL, e) Total cost, f) Economic saving by the use of LED versus FL and g) Present value of the difference between costs and benefits.

measurements, confirming what was reported in previous studies $[10,21]$.

Several authors have proposed the adoption of LED lighting as an alternative to the reduction of energy consumption in educational facilities [1,4,5,18,21]. However, these studies start from the use of a specific luminaire model, devaluing the analysis of other alternatives through a multicriteria decision method. In this research, the application of the AHP method for this purpose demonstrated feasibility and relevance. In the same way, the lamps selection criteria here used and their respective levels of relative importance may constitute a starting point for future research to strengthen lamp selection decisions.

Another important element to highlight is that the studies that have validated the implementation of indoor LED lighting systems as the best strategy against traditional lighting technologies $[1,4,5,9,18]$, do not consider the costs of the final disposal of a massive FL replacement. Fluorescent and compact fluorescent lamps contain Mercury, a potentially dangerous element for the environment, so the final disposal of these lamps must be handled carefully through special recycling techniques $[2,3]$. For this reason, in this research when estimating the costs for each alternative, in addition to the acquisition costs and the annual energy consumption, the cost of the final disposal of the replaced FL was included.

In the economic analysis of alternative lighting systems for interiors, it is common to calculate the Simple Payback Period (SPBP) or the whole lifecycle cost (WLC) without considering the value of money in the time $[1,4,10,19]$, although some authors consider that these techniques should not be used as the primary measure of value to select a project alternative $[15,16]$. The consideration of the net present value (NPV) or the equivalent annual uniform cost (EAUC) as economic evaluation tools is not common in the literature.

In this context, the strategy of progressive change to LED lighting proposed in this research yielded a VPN of $\$ 56115.02$. This means that if the institution had to disburse today the amount required to cover the lighting costs of the next eight years, it would be more economical to have a lighting system based on LED technology since maintaining the current FL-based system would be $42 \%$ more expensive. Likewise, for the first strategy, the estimated EAUC was $\$ 8868.28$, less than the value of $\$ 20669.26$ which would represent maintaining the current system based on FL technology. This allows validating that the first alternative is more feasible from the economic point of view, and at the same time confirms the relevance of the VPN and the EAUC as economic evaluation tools for mutually exclusive investment project alternatives with different life cycles where generally only the costs are relevant.

Finally, the authors would like to point out that the reduction of energy consumption in a university campus, not only depends on the implementation of strategies such as the adoption of a more efficient and safe lighting system like the one suggested in this work. Energy-saving must be a shared social responsibility of all those who make the University a common resource for the entire Society. In this regard, HEIs should take advantage of their transformative capacity to raise awareness among their students, teachers and administrative staff about the need to contribute to energy savings and thereby maximize the contribution that is made from the academy towards environmental sustainability.

\section{Conclusions}

This work showed that despite the high cost of LED lighting, it is feasible from a technical and economic point of view to converting an FL lighting system set in educational institutions through the implementation of a progressive replacement strategy. The suggested strategy guarantees the total replacement of the current lighting system of a university building consisting of 215 light points and $2595 \mathrm{FL}$, in three years, with an initial investment of 4949.10 USD, generating an energy saving of $47.36 \%$.

Through simulation in DIALux 4.12, it was demonstrated that the proposed LED lighting system will cover the minimum indoor lighting levels established in national and international regulations for educational facilities. The estimation of the investment net present value, as well as its equivalent annual uniform cost, proved the economic feasibility of the improvement proposal.

The results of this work could constitute a reference for the administrative management of public universities in developing countries, which increasingly receive fewer resources from governments. The economic savings for the implementation of 367 
more efficient lighting systems could contribute to the strengthening of university infrastructure and the offering of better educational services. At the same time, the energy savings generated would have a positive impact on the reduction of the emission of greenhouse gases into the atmosphere. In this regard, future research should pay more attention to the combination of more efficient lighting systems with cleaner energy sources, to maximize the contribution that is made from the academy to the sustainability of the environment.

\section{Conflict of Interest}

The authors declare no conflict of interest.

\section{Acknowledgment}

Authors would like to thank Universidad Politécnica Salesiana for funding this research under the resolution No. 03-006-201705-30 of Guayaquil Campus Research Council. Also, a special acknowledge is dedicated to all the industrial engineering students who helped to collect relevant data for the lighting audit in all the facilities of the academic building.

\section{References}

[1] N. Tshikuvhe, M. Nthontho, S. P. Chowdhury, S. Chowdhury, "Cost effective carbon mitigation through energy efficiency: A case for a university student residence lighting in Cape Town," in 2013 IEEE African Conference (Africon), Pointe-Aux-Piments, Mauritius, 2013. https://doi.org/ 10.1109/AFRCON.2013.6757686

[2] M. M. Aman, G. B. Jasmon, H. Mokhlis, A. H. A. Bakar, "Analysis of the performance of domestic lighting lamps," Energ. Policy, 52, 482-500, 2013. https://doi.org/ 10.1016/j.enpol.2012.09.068

[3] B. Gayral, "LEDs for lighting: Basic physics and prospects for energy savings," Comptes Rendus Phys., vol. 18, no. 7-8, pp. 453-461, Sep. 2017. https://doi.org/10.1016/j.crhy.2017.09.001

[4] F. Salata, I. Golasi, M. di Salvatore, and A. de Lieto Vollaro, "Energy and reliability optimization of a system that combines daylighting and artificial sources. A case study carried out in academic buildings," Appl. Energ, 169, 250-266, 2016. https://doi.org/10.1016/j.apenergy.2016.02.022

[5] P. Sathya, R. Natarajan, "Energy estimation and photometric measurements of LED lighting in laboratory," in 2014 International Conference on Advances in Electrical Engineering (ICAEE), Tamilnadu, India, 2014. https://doi.org/10.1109/ICAEE.2014.6838470

[6] B. Atanasiu, C. Despret, M. Economidou, J. Maio, I. Nolte, O. Rapf, "Europe's Buildings under the Microscope: A Country-by-Country Review of the Energy Performance of Buildings,” Build. Perform. Inst. Eur., 2011.

[7] J. Min, I. L. Azevedo, P. Hakkarainen, "Assessing regional differences in lighting heat replacement effects in residential buildings across the United States," Appl. Energy, 141, 12-18, 2015. https://doi.org/10.1016/ J.APENERGY.2014.11.031

[8] Y. Nikolaidis, P. A. Pilavachi, A. Chletsis, "Economic evaluation of energy saving measures in a common type of Greek building," Appl. Energy, vol. 86(12), 2550-2559, 2009. https://doi.org/10.1016/J.APENERGY.2009.04. 029

[9] S. Ji, G. Cao, J. Zhang, F. Yu, D. Li, J. Yu, "Lighting design of underground parking with tubular daylighting devices and LEDs," Opt. - Int. J. Light Electron Opt., 127(3), 1213-1216, 2016. https://doi.org/10.1016/j.ijleo. 2015.10.189

[10] P. K. Soori S. Alzubaidi, "Study on improving the energy efficiency of office building's lighting system design" in 2011 IEEE GCC Conference and Exhibition, 2011. https://doi.org/10.1109/IEEEGCC.2011.5752604

[11] D. Singh, C. Basu, M. Meinhardt-Wollweber, B. Roth, "LEDs for energy efficient greenhouse lighting," Renew. Sustain. Energy Rev., 49, 139-147, 2015. https://doi.org/10.1016/j.rser.2015.04.117

[12] Comisión de Normalización Europea, Iluminación de los lugares de trabajo en interiores. Unión Europea, 2002.

[13] Instituto Ecuatoriano de Seguridad Social, Reglamento de Seguridad y salud de los trabajadores y mejoramiento del ambiente de trabajo. Ecuador, 1986.

[14] T. L. Saaty, "Decision making with the analytic hierarchy process," Int. J.
Serv. Sci., 1(1), 83-98, 2008.

[15] N. Sapag Chain, R. Sapag Chain, Preparación y evaluación de proyectos, McGraw Hill Interamericana, 2008.

[16] L. Blank and A. Tarquin, Ingeniería Económica. McGraw-Hill Interamericana, 2006.

[17] Banco Central del Ecuador, Información económica, 2018. Available: https://www.bce.fin.ec/index.php/informacioneconomica.

[18] L. Alboteanu, G. Manolea, "Photovoltaic lighting for an educational room," in 2013 4th International Symposium on Electrical and Electronics Engineering (ISEEE), Galati, Romania, 2013. https://doi.org/ 10.1109/IEEEGCC.2011.5752604

[19] S. Alzubaidi, P. K. Soori, "Energy Efficient Lighting System Design for Hospitals Diagnostic and Treatment Room-A Case Study,” J. Light Vis. Environ., 36(1), 23-31, 2012. https://doi.org/10.2150/jlve.36.23

[20] L. E. Mavromatidis, X. Marsault, H. Lequay, "Daylight factor estimation at an early design stage to reduce buildings' energy consumption due to artificial lighting: A numerical approach based on Doehlert and BoxBehnken designs," Energy, 65, 488-502, 2014. https://doi.org/ 10.1016/j.energy.2013.12.028

[21] K. Zalatis, K. Berzina, "Effective and optimal simulation of light design in Riga Technical university's lighting laboratory from the point of view of energy efficiency," in 2016 IEEE 4th Workshop on Advances in Information, Electronic and Electrical Engineering (AIEEE), Vilnius, Lithuania, 2016. https://doi.org/10.1109/AIEEE.2016.7821822 